Corrigendum

\title{
Corrigendum to "Radiological Features of Gastrointestinal Lymphoma”
}

\section{Giuseppe Lo Re, Federica Vernuccio, Federico Midiri, Dario Picone, Giuseppe La Tona, Massimo Galia, Antonio Lo Casto, Roberto Lagalla, and Massimo Midiri}

Radiology Section, DIBIMED, University of Palermo, Via del Vespro 129, 90127 Palermo, Italy

Correspondence should be addressed to Federica Vernuccio; federicavernuccio@gmail.com

Received 17 August 2016; Accepted 6 September 2016

Copyright (C) 2016 Giuseppe Lo Re et al. This is an open access article distributed under the Creative Commons Attribution License, which permits unrestricted use, distribution, and reproduction in any medium, provided the original work is properly cited.

In the article titled "Radiological Features of Gastrointestinal Lymphoma" [1], the name of the second author was given incorrectly, with the first and last names reversed. The revised author list is shown above.

\section{References}

[1] G. Lo Re, V. Federica, F. Midiri et al., "Radiological features of gastrointestinal lymphoma," Gastroenterology Research and Practice, vol. 2016, Article ID 2498143, 9 pages, 2016. 


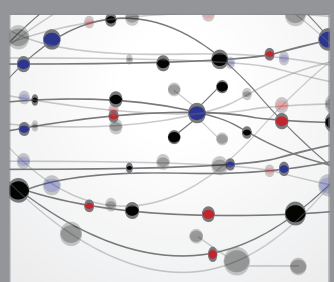

The Scientific World Journal
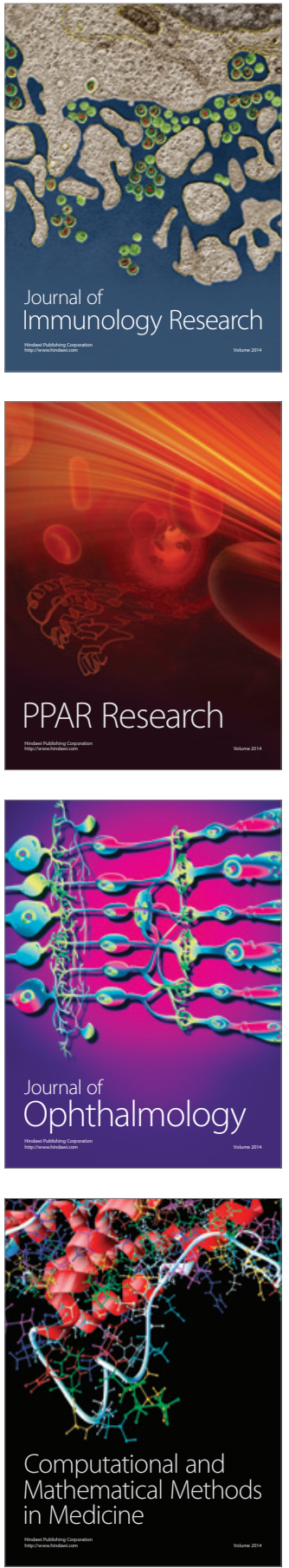

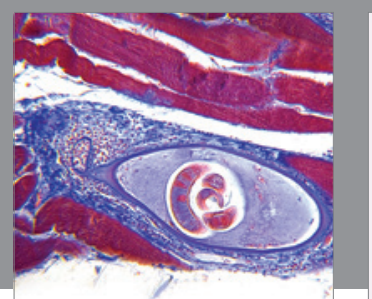

Gastroenterology Research and Practice

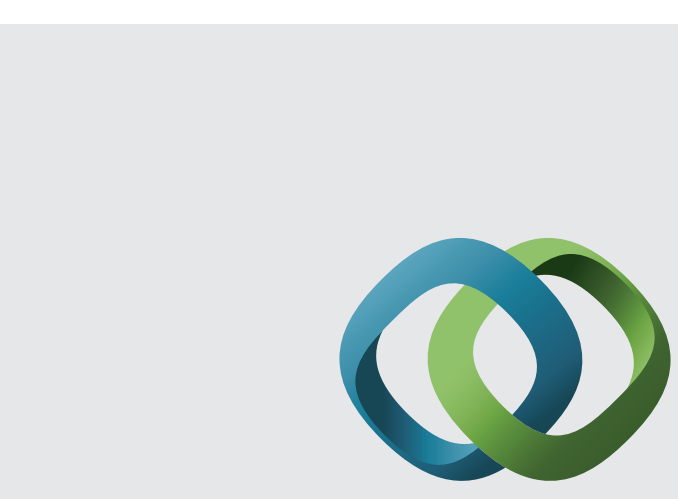

\section{Hindawi}

Submit your manuscripts at

http://www.hindawi.com
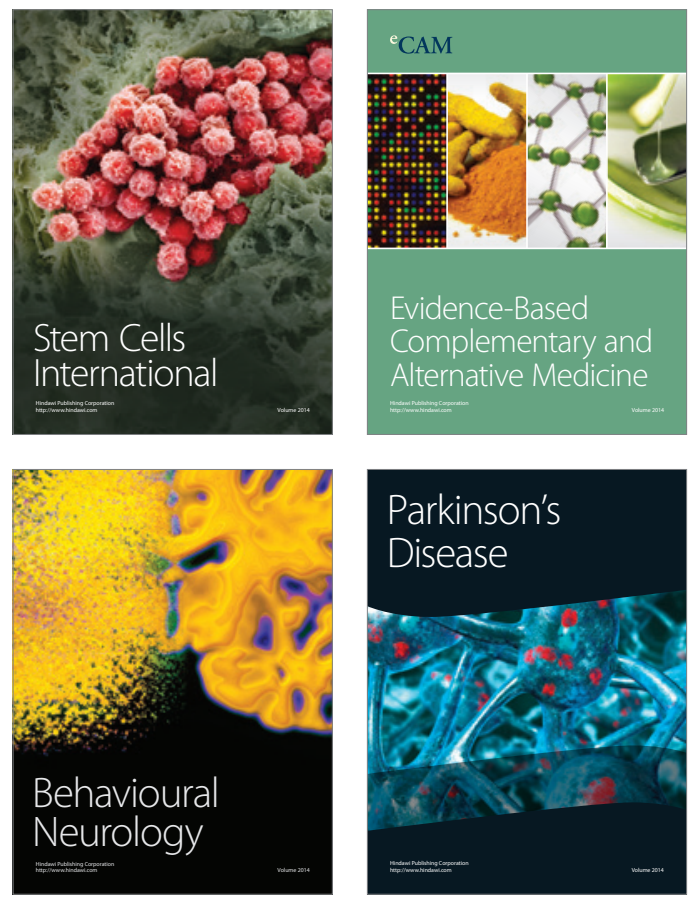
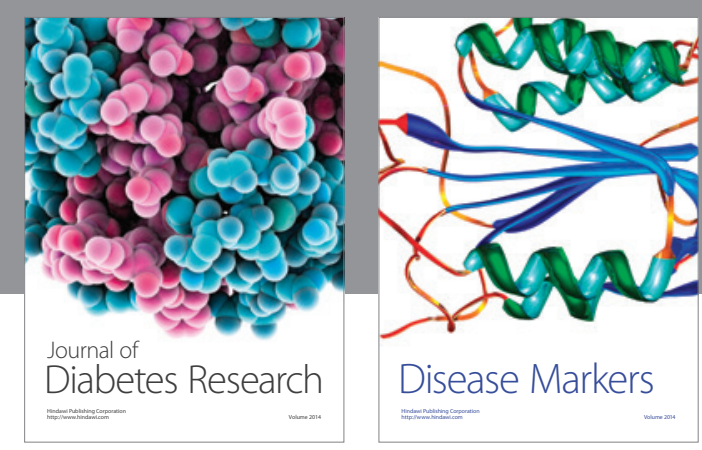

Disease Markers
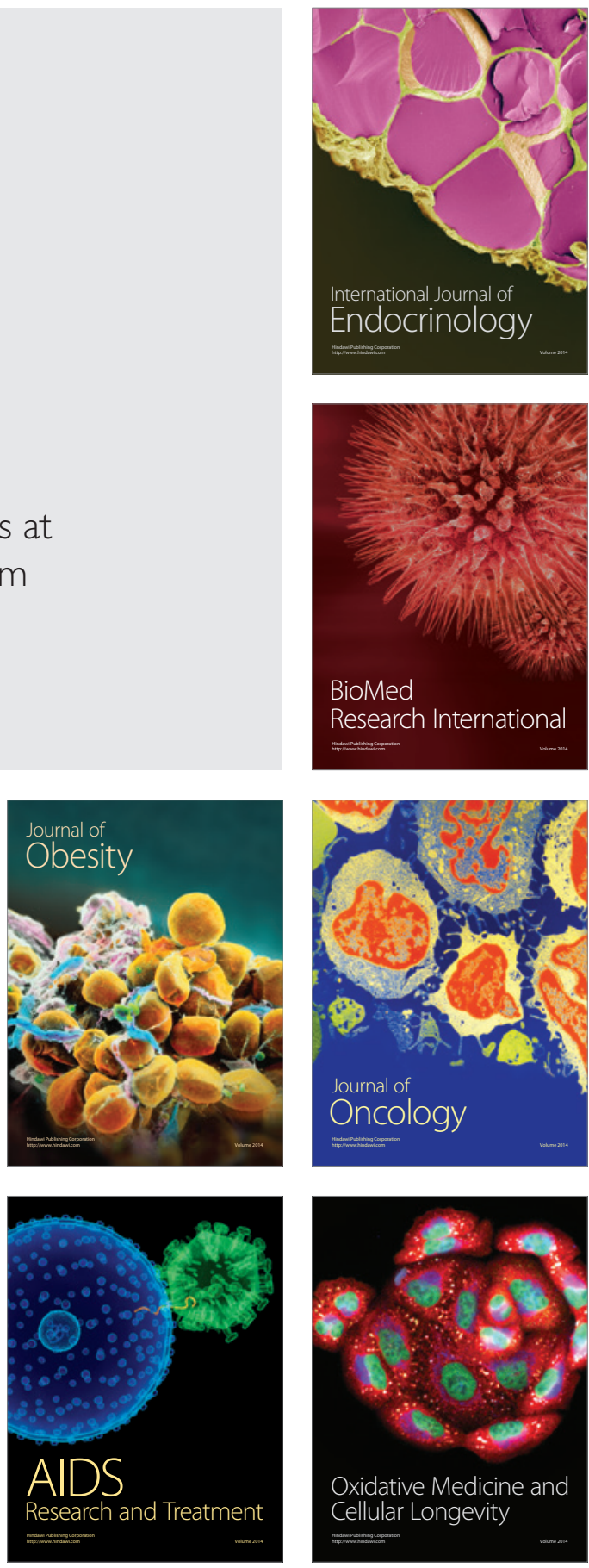